\title{
OBSERVATIONAL STUDY OF FREQUENT DEGENERATIVE LOW BACK PAIN SYNDROMES ON PATIENTS UNDER BALNEAL TREATMENT
}

\section{Lupu Andreea ${ }^{12}$, Ionescu Elena Valentina ${ }^{13}$, Iliescu Madalina Gabriela ${ }^{13}$, Botnarciuc Mihaela ${ }^{1}$,Iliescu Dan Marcel', Ion Ileana'}

1 "Ovidius" University of Constanţa, Faculty of Medicine

2 Emergency County Hospital "St. Andrew" Constanta

${ }^{3}$ Balneal and Rehabilitation Sanatorium of Techirghiol

\begin{abstract}
Degenerative low back pain is one of the most important causes of disability worldwide, and it also has a negative impact on the economy, due to the high cost of medical care required for this pathology. It has an increased prevalence among the population, between 80-85\%, it affects population between 45 and 65 years old, and the most frequent cause is the mechanical one, with degenerative syndromes on the first place. Balneal treatment is a complex treatment with multiple benefits for patients with degenerative low back pain syndromes, and in the recent years this topic is intensely studied due to its benefits, as well as the increased addressability of the patients for this type of treatment. Our study evaluated 99 patients with low back pain divided into 2 groups of patients admitted for 2 weeks to Balneal and Rehabilitation Sanatorium of Techirghiol, who performed balneal treatment with hot mud baths and cold mud baths, but also classic rehabilitation treatment (electrotherapy, masotherapy, kinetotherapy, thermotherapy). The aim of the study was to evaluate the characteristics of degenerative low back pain syndromes on patients under balneal treatment, and for the patients from our study the most frequent pathology was Spondilosis, female patients was predominantly affected than male patients, with high education level and from urban residence.
\end{abstract}

Keywords: low back pain, Techirghiol, rehabilitation treatment, balneal treatment.

\section{Introduction}

Degenerative low back pain is one of the most important causes of disability worldwide, according to the Global Burden of Disease (GBD), and it also has a negative impact on the economy due to the high cost of medical care needed for this pathology. In 2017, GBD published a disability report analyzing 328 illnesses during 1990-2016, and it was discovered that low back pain, among migraine, age related hearing loss or due to other causes, iron-deficiency anemia and major depressive syndromes were the 5 leading causes of global disability (1). Degenerative low back pain may be associated with a variety of symptoms that may include pain in the lower extremity of the body, with or without lower limb irradiation, muscle weakness, lumbosacral pain, and pain can have varying degrees of intensity. Lumbar degenerative pathology may reduce the quality of life of patients with this pathology (2). Another important problem of low back pain is the numerous people suffering from this condition, studies have shown that its prevalence is between $80-85 \%$ reported to the globe population $(3,4,5)$. The incidence of this disease is higher among women than among men $(1,3)$. It is the fifth cause which determine a visit to a physician and the third cause of physical disorder among the 4565 years-old population. The mechanical cause 
appears to be responsible for $90 \%$ of the cases of low back pain, which includes the degenerative pathology, with an increased frequency among the mechanical causes. Mechanical low back pain occurs due to problems in the structures of the spine, such as ligaments, joints, periosteum, paravertebral muscles, or nerve tracts. The most common cause of pain is osteoarthritis of the lumbosacral column, which determine bone, articular or ligament degeneration (3). Degenerative low back pain pathology includes disorders such as spondylolisthesis, intervertebral disc degeneration or lumbar canal stenosis (2). Balneal treatment represents an option of treatment for patients with degenerative pain, and mud treatments have been extensively studied in recent years due to its multiple properties and benefits to patients with such disorders (6). Balneal treatment is a complex treatment that combines the classical rehabilitation treatments: electrotherapy, masotherapy, thermotherapy, kinetotherapy, hydrokinetotherapy, and sapropelic mud treatments such as hot mud baths or cold mud baths. The Balneal and Rehabilitation Sanatorium of Techirghiol offers this type of treatment for its patients. From the Sanatorium studies, the most common pathology is degenerative locomotor pathology, and lumbar pain it represents a frequent cause of addressability, followed by knee pain and cervical pain. The aim of our study is to evaluate the characteristics of degenerative low back pain syndromes of patients with low back pain following balneal rehabilitation treatment.

\section{Material and methods}

The study was conducted on a total of 99 patients admitted to the Balneal and Rehabilition Sanatorium of Techirghiol for a period of 2 weeks. All patients received the information needed to conduct the study and signed an informed consent. The patients enrolled in the study were only patients with chronic degenerative low back pain who had no other conditions or pathologies that could contraindicate the balneal rehabilitation treatment. The exclusion criteria of the study consisted in any type of condition, or pathology that may contraindicate the treatment, such as the presence of any inflammatory syndrome, decompensated cardiovascular, pulmonary, renal, digestive, neurological pathologies, any neoplasms or any skin lesions. The patients in the study were divided into 2 groups: the hot mud baths group (HMB) and the cold mud baths group (CMB). All patients received electrotherapy treatment (low, medium or high frequency), masotherapy and kinetotherapy. The hot mud baths group received mud treatment in the tube, and the cold mud bath group did the mud treatment on the shore of Lake Techirghiol. Each patient from the study was clinically examined and completed a questionnaire that included demographic data (age, gender, educational level, history of low back pain, frequency of balneal treatment).

\section{Results}

The demographic data of the patients in the study were detailed in the following table and includes data of the patients such as gender, residency, educational level, professional status (Table 1).

Table 1 -Demographic characteristics of the patients in the study

\begin{tabular}{|l|l|c|c|c|c|}
\hline \multirow{2}{*}{} & \multicolumn{4}{|c|}{ Groups } \\
\cline { 3 - 6 } & \multicolumn{2}{|c|}{ Hot mud baths } & \multicolumn{2}{c|}{$\begin{array}{c}\text { Cold mud } \\
\text { baths }\end{array}$} \\
\cline { 3 - 6 } & & Count & $\%$ & Count & $\%$ \\
\hline \multirow{2}{*}{ Gender } & Total & 51 & & 48 & \\
\hline \multirow{2}{*}{ Residence } & Feminin & 32 & $62.7 \%$ & 31 & $64.6 \%$ \\
\cline { 2 - 6 } & Uasculin & 19 & $37.3 \%$ & 17 & $35.4 \%$ \\
\cline { 2 - 6 } & Rurban & 43 & $84.3 \%$ & 42 & $87.5 \%$ \\
\hline \multirow{2}{*}{$\begin{array}{l}\text { Educational } \\
\text { level }\end{array}$} & Gymnasium & 2 & $3.9 \%$ & 3 & $6.3 \%$ \\
\cline { 2 - 6 } & High school & 15 & $29.4 \%$ & 12 & $25 \%$ \\
\cline { 2 - 6 } & Faculty & 34 & $66.7 \%$ & 33 & $68.8 \%$ \\
\hline \multirow{2}{*}{$\begin{array}{l}\text { Proffesional } \\
\text { status }\end{array}$} & Employed & 29 & $56.9 \%$ & 28 & $58.3 \%$ \\
\cline { 2 - 6 } & Unemployed & 3 & $5.9 \%$ & 2 & $4.2 \%$ \\
\cline { 2 - 6 } & Retired & 19 & $37.3 \%$ & 18 & $37.5 \%$ \\
\hline
\end{tabular}

The 99 patients from the study were divided as following: 51 patients were from the hot mud baths group and 48 patients were from the cold mud baths group. Analyzing patient data, it was found that the majority were women in each group, $62.7 \%$ from the hot mud baths group and $64.6 \%$ from the cold mud baths group. Regarding the residence of the patients, most of the patients had urban residence, $84.3 \%$ of the patients from 
the HMB group and $87.5 \%$ of patients from the CMB group. Analyzing the groups in terms of educational level, over $50 \%$ of them have high level education: $66.7 \%$ of the HMB group and $68.8 \%$ of the CMB group. Regarding the professional status of the patients, over $50 \%$ of them were employed at the time of the study: $56.9 \%$ of patients from the HMB group and $58.3 \%$ of patients from $\mathrm{CMB}$ group. Analyzing the age of patients from the study, it was found that the average age was 56.26 years old, as detailed in the table 2, below: 55.71 average age in the HMB group and 56.81 average age in the CMB group.

Table 2 - Patient's age from the study groups

\begin{tabular}{|l|r|r|}
\hline Group & Hot mud baths & Cold mud baths \\
\hline $\mathrm{N}$ & 51 & 48 \\
\hline Minimum & 29 & 42 \\
\hline Maximum & 70 & 70 \\
\hline Mean & 55.71 & 56.81 \\
\hline Std. Deviation & 9.462 & 7.431 \\
\hline
\end{tabular}

Patients were asked when the low back pain occurred and if the lumbar pain occurred after a solicitation of the lumbar column, and the data is detailed in the following table (Table 3).

Table 3 - Pain history and debut of low back pain of patients from the study

\begin{tabular}{|l|l|c|c|c|c|}
\hline \multirow{2}{*}{} & \multicolumn{4}{|c|}{ Groups } \\
\cline { 3 - 6 } \multicolumn{2}{|c|}{} & \multicolumn{2}{|c|}{ Hot mud baths } & \multicolumn{2}{c|}{ Cold mud baths } \\
\cline { 2 - 6 } & Count & $\%$ & Count & $\%$ \\
\hline \multirow{3}{*}{$\begin{array}{l}\text { Lumbar } \\
\text { pain history }\end{array}$} & -1 year & 5 & $9.8 \%$ & 4 & $8.3 \%$ \\
\cline { 2 - 6 } & $1-5$ years & 16 & $31.4 \%$ & 11 & $22.9 \%$ \\
\cline { 2 - 6 } & $>5$ years & 30 & $58.8 \%$ & 33 & $68.8 \%$ \\
\hline $\begin{array}{l}\text { Debut after } \\
\text { lumbar } \\
\text { solicitation }\end{array}$ & Yes & 40 & $78.4 \%$ & 35 & $72.9 \%$ \\
\cline { 2 - 6 } & No & 11 & $21.6 \%$ & 13 & $27.1 \%$ \\
\hline
\end{tabular}

Painful lumbar history was more than 5 years for over $50 \%$ of patients: $58.8 \%$ of patients from the HMB group and $68.8 \%$ of patients from the CMB group. The debut of lumbar pathology after a solicitation of lumbar column was found in a large number of patients: $78.4 \%$ of patients from the HMB group and $72.9 \%$ of patients from the CMB group. The frequency of treatment of the patients from the study groups was also analyzed and is detailed in Table 4.

Table 4-Frequency of balneal treatment of the patients from the study

\begin{tabular}{|l|c|c|c|c|c|}
\hline \multirow{2}{*}{} & \multicolumn{4}{|c|}{ Groups } \\
\cline { 3 - 6 } & \multicolumn{2}{|c|}{ Hot mud baths } & \multicolumn{2}{c|}{ Cold mud baths } \\
\cline { 3 - 6 } & Count & $\%$ & Count & $\%$ \\
\hline \multirow{3}{*}{$\begin{array}{l}\text { Frequency of } \\
\text { treatment }\end{array}$} & Biannual & 9 & $17.6 \%$ & 2 & $4.2 \%$ \\
\cline { 2 - 6 } & Annual & 19 & $37.3 \%$ & 29 & $60.4 \%$ \\
\cline { 2 - 6 } & Ocasional & 5 & $9.8 \%$ & 0 & $0 \%$ \\
\cline { 2 - 6 } & First time & 18 & $35.3 \%$ & 17 & $35.4 \%$ \\
\hline
\end{tabular}

Table IV shows that patients from the study performed annual treatment as follows: $37.3 \%$ of patients from the HMB group and $60.4 \%$ of patients from the CMB group. The percent of patients who have received biannual treatment is quite small $(17.6 \%$ of patients from the HMB group and $4.2 \%$ of patients from the CMB group), compared to the patients who came for the first time for balneal treatment $335.3 \%$ of patients from the HMB group and $35.4 \%$ of patients from the CMB group). Regarding the patient's pathology, the most frequent diagnosis was Spondilosis: 27 (52.9\%) patients from HMB group and $30(62.5 \%)$ patients from CMB group. Phase III Discopathy had a higher percentage (23.5\% in HMB group and $16.7 \%$ in $\mathrm{CMB}$ group) compared to Phase II Discopathy (17.6\% in $\mathrm{HMB}$ group and $12.5 \%$ in CMB group), and

Table 5 -Degenerative low back pain syndromes of the patients from the study

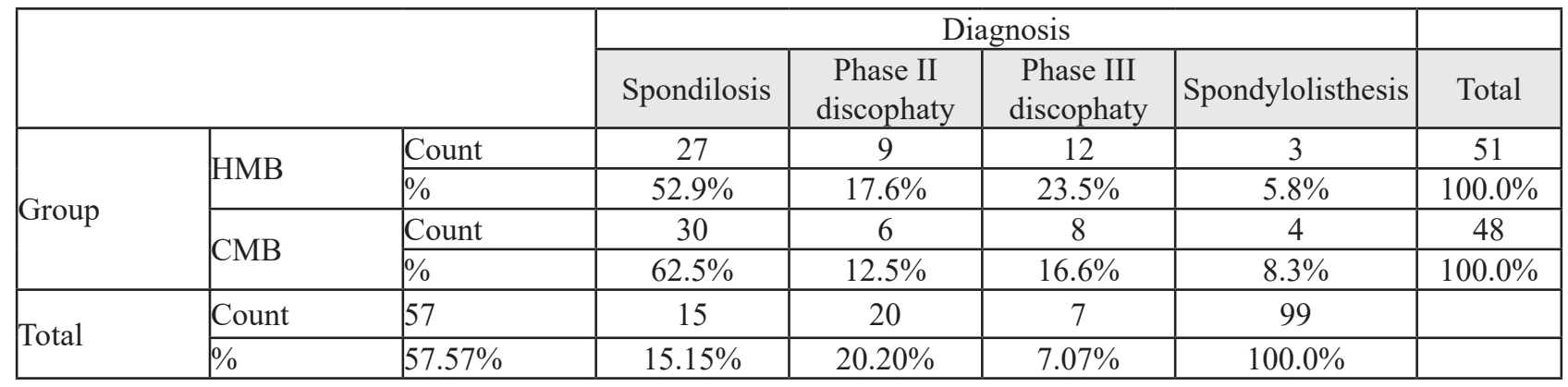


Spondylolisthesis has a lower frequency among the patients from the study $(5.9 \%$ in HMB group and $8.3 \%$ in CMB group) (Figure 1 and Table 5).

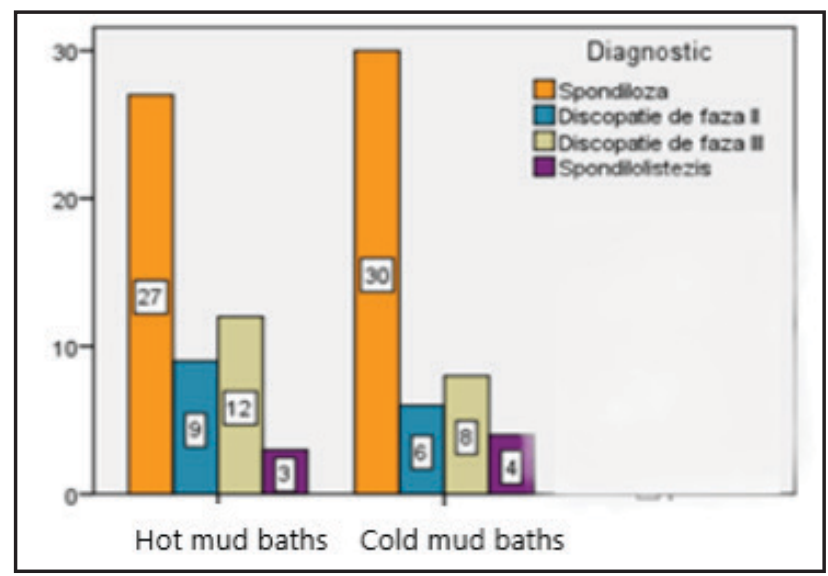

Figure 1 - Graphic representation of degenerative low back pain syndromes of the patients from the study

Patients from the study have performed, beside hot and cold mud baths, classical rehabilitation therapies: low frequency electrotherapy - galvanic current (CG), galvanic bath (BG), diadinamic current (CDD), TENS current (TENS); mid- frequency electrotherapy - interferential current (CIF); high-frequency electrotherapy - short waves (US); ultrasound (U); laser therapy (L); magnetotherapy (MDF); thermotherapy - paraffin cataplasm (CP); hydrotherapy (DS). All patients from the study performed masotherapy and kinetotherapy (Table $6)$.

Table 6-Distribution of patients from the study according to the treatments performed

\begin{tabular}{|l|c|c|c|c|c|c|}
\hline & \multicolumn{5}{|c|}{ Groups } & \multicolumn{2}{c|}{} \\
\hline & \multicolumn{2}{|c|}{ HMB } & \multicolumn{2}{c|}{ CMB } & \multicolumn{2}{c|}{ Total } \\
\hline & Count & $\%$ & Count & $\%$ & Count & $\%$ \\
\hline CG & 10 & $7.70 \%$ & 14 & $10.80 \%$ & 24 & $18.50 \%$ \\
\hline BG & 16 & $12.30 \%$ & 14 & $10.80 \%$ & 30 & $23.10 \%$ \\
\hline CDD & 16 & $12.30 \%$ & 13 & $10.00 \%$ & 29 & $22.30 \%$ \\
\hline TENS & 2 & $1.50 \%$ & 0 & $0.00 \%$ & 2 & $1.50 \%$ \\
\hline CIF & 46 & $35.40 \%$ & 42 & $32.30 \%$ & 88 & $67.70 \%$ \\
\hline L & 28 & $21.50 \%$ & 31 & $23.80 \%$ & 59 & $45.30 \%$ \\
\hline U & 25 & $19.20 \%$ & 23 & $17.70 \%$ & 48 & $36.90 \%$ \\
\hline MDF & 40 & $30.80 \%$ & 33 & $25.40 \%$ & 73 & $56.20 \%$ \\
\hline US & 9 & $6.90 \%$ & 6 & $4.60 \%$ & 15 & $11.50 \%$ \\
\hline DS & 4 & $3.10 \%$ & 5 & $3.80 \%$ & 9 & $6.90 \%$ \\
\hline CP & 9 & $6.90 \%$ & 8 & $6.20 \%$ & 17 & $13.10 \%$ \\
\hline
\end{tabular}

Analyzing the types of treatment performed by the patients from the study, a large number of patients had medium-frequency electrotherapy - $67.7 \%$ of them, magnetotherapy performed $56.2 \%$ of patients, laser therapy had $45.3 \%$ of patients and ultrasound therapy $36.9 \%$ of patients. Remaining therapies has less than 30\%. As we can see there is a high percentage of antialgic therapies, which patients tolerate better and the pain is decreasing rapidly after this kind of therapies.

\section{Discussions}

From the analysis of the two study groups there was found an increased frequency of female patients for rehabilitation treatment, which confirms the higher percentage of the degenerative low back pain syndromes among female population $(1,3)$, but also the higher addressability of the female patients to rehabilitation treatments (8). The majority of patients here from urban residence compared to the small number of patients with rural residence, which was also showed in other studies (7), and this is probably due to lower educational and medical level, but also due to socio-economic disadvantages of the patients from rural residence (8). Regarding the educational level, over $50 \%$ of patients form the study have high level education, which shows that people with a high level education pay more attention to health problems, have a high medical level education and are more concerned with their health rather than lower educational level persons. Average age of patients from the study was 56.49 years, which confirms that patients with degenerative low back pain syndromes are between 45 and 65 years old, regarding the last studies (3). Over 55\% of patients from the study have a history of low back pain for more than 5 years, and about the same percentage perform annual rehabilitation treatment, although rehabilitation treatments are indicated at 6 months. From the low back pain syndromes, the lumbar Spondylosis was the most frequent, over $50 \%$ among the patients from the study, followed by Lumbar Discopathies phase II and III. From what we know so far, there have been no studies showing the rate of degenerative syndromes for patients with low back pain, only the frequency of mechanical cause, which was also showed for the patients from our study 
with the high rate of painful debuts after lumbar solicitation (over $70 \%$ of patients from the study) (3). Balneal and rehabilitation treatments are increasingly studied over the past few years, but their benefits are still not fully known, and further studies would be needed to demonstrate their benefits for the patients with degenerative low back pain syndromes, which are so frequent among the population.

\section{Conclusions}

Analyzing the data from our study, it was found that the most frequent degenerative low back pain syndrome is Spondylosis. It is more common in women, probably due to the fact that the addressability to rehabilitation treatments is higher among women. Most of our patients were from urban residence, and had a painful lumbar history for over 5 years, and regarding the frequency of balneal treatment, most of them came annually.

\section{Acknowledgements}

This study was conducted with the significant implication of the Scientific Research Nucleus from Balneal and Rehabilitation Sanatorium of Techirghiol.

\section{References}

1. Vos T., Abajobir A.A., Abbafati C. et all - Global, regional, and national incidence, prevalence, and years lived with disability for 328 diseases and injuries for 195 countries, 1990-2016: a systematic analysis for the Global Burden of Disease Study 2016 - The Lancet, 2017, 390 (10100), 1211-1259.

2. Ravinda V.M., Senglaub S.S., Rattani A., et all - Degenerative lumbar spine disease: estimating global incidence and worldwide volume - Global Spine Journal, 2018, Vol.8(8), 784-794.

3. Diamond S., Borenstein D. - Chronic low back pain in a working-age adult - Best practice \& research clinical rheumatology, 2006, 20 (4), 707-720.

4. Braddom R.L, Chan L., Harrast M.A., Kowalske K.J., Matthews D.J., Ragnarsson
K.T., Stolp K. - Medicină Fizică și de Reabilitare , Ediția a IV-a, București, 2015, 978-973-0-19869-0.

5. Dunn K.M., Hestbaek L., Cassidy J.D.Low back pain across the life course - Best Practice \& Research Clinical Rheumatology, 2013, 27, 591-600.

6. Lupu A.A., Ionescu E.V., Iliescu M.G., Almasan R.E., Oprea C, Ion I., Iliescu D.M. - Effects of Techirghiol specific climate factors on the patients quality of life with degenerative lumbar pain - Journal of envirnmental protection and ecology, 2018, 19 (4), 1857-1863.

7. Iliescu M.G., Profir D., Surdu O., Marin V., Demirgean S., Almasan R.E., Stanciu L.E:, Oprea C., Iliescu D.M., Ionescu E.V. - Statistical view through balneal activity in Techirghiol medical area - Journal of environmental protection and ecology, 2018, 19 (1), 382-391.

8. Oprea C., Ionescu E.V., Iliescu M.G., Almasan R.E., Calota N., Iliescu D.M. - Monitoring and evaluation of patient's satisfaction in medical units that use natural factors for treatment - Journal of environmental protection and ecology, 2019, 20(1): 447-452. 